J. Amer. Soc. Hort. Sci. 120(2): 134-138. 1995.

\title{
Changes in Water Status of Peach Flower Buds During Endodormancy and Ecodormancy Measured by Differential Scanning Calorimetry and Nuclear Magnetic Resonance Spectroscopy
}

\author{
Toshihiko Sugiura \\ Fruit Tree Research Station, Tsukuba, Ibaraki, 305 Japan \\ Mitsuru Yoshida \\ National Institute of Agro-Environmental Sciences, Tsukuba, Ibaraki, 305 Japan \\ Jun Magoshi \\ National Institute of Agrobiological Resources, Tsukuba, Ibaraki, 305 Japan \\ Sukeyuki Ono \\ Fruit Tree Research Station, Tsukuba, Ibaraki, 305 Japan
}

Additional index words. developmental stage. Prunus persica

\begin{abstract}
Physiological changes in 'Hakuho' peach [Prunus persica (L.) Hatsch] flower buds during endodormancy and ecodormancy were investigated based on their water status measured by differential scanning calorimetry (DSC) and nuclear magnetic resonance (NMR) spectroscopy. The developmental stage in ecodormancy, which was estimated as the number of days between the sampling date for shoots and the bloom date after forcing, was dominated by absorption of water and was closely related to the water content per dry weight. Two types of water differing in spin-lattice relaxation time (T1) of protons were detected in the flower buds. Water with the shorter T1 was considered to be freezing water as well as that with a longer T1. Nonfreezing water can not be detected by NMR. The change in the longer T1 coincided with the change in the water percentage relative to bud fresh weight and reflected the physiological development in ecodormancy. The shorter T1 value started to increase shortly before rest break and may have some relation with the physiological change at rest break.
\end{abstract}

The buds of most deciduous trees show no visible growth soon after their formation in the autumn, even if the temperature is favorable for bloom (endodormancy). Endodormancy is broken by a certain amount of chilling temperature (Chandler and Tufts, 1934). The period following endodormancy and before bud break. when buds remain dormant because ambient temperatures are unfavorable for growth, is endodormancy.

Information on the developmental stages of buds is useful in horticulture for estimating the flowering date in orchards and determining the time when heating should be started for greenhouse forcing. The progress in the developmental stage cannot be determined clearly from the appearance of buds. However, some cellular components change throughout endo- and ecodormancy. For example, the abscisic acid (ABA) level. which has been studied in buds of several species. is highest at the time of leaf fall during endodormancy and decreases throughout ecodormancy (Corgun and Peyton. 1970: Harrison and Saunders. 1975: Mielkc and Dennis. 1975; Wright. 1975: Seeley and Powell. 1981). It has also been reported that sour cherry flower buds accumulate starch during endodormancy (Felker et al.. 1983), and desaturated membrane lipids in apple buds increase during endo- and ecodormancy (Wang and Faust, 1990). Since water is the main solvent for these cellular components responsible for physiological development. changes in the mobility of the water in bud tissues are expected to

Received for publication 25 Oct. 1994. Acceped for publication 18 July 1994. Contribution no. A-317 of Fruit Tree Research Station. The cost of publishing this paper was defrayed in part by the payment of page charges. Under postal regulations. this paper therefore must be hereby marked advertisement solely to indicate this fact. accompany the physiological changes. We therefore investigated the water status of flower buds to detect the physiological changes occurring during development toward bud break.

The water status of biological samples can be measured by means of nondestructive methods, such as nuclear magnetic resonance (NMR) spectroscopy. The NMR relaxation times of water protons reflect the motion of water molecules in tissues (MathurDe Vre. 1984). Several types of water with different relaxation times indicating differing molecular mobility are usually found in living samples. The water in different physical status is detected by differential scanning calorimetry (DSC) based on the melting or crystallization heat curve characteristics. Thus, we can identify water in living samples according to this property.

In this research we investigated the water status of peach flower buds by NMR and DSC during endodormancy and ecodormancy.

\section{Materials and Methods}

Plant materials Ten first-year shoots, 30 to $40 \mathrm{~cm}$ in length. were randomly collected twice a month from 5 Dec. 1989 to 26 Mar. 1990 from 9-year-old 'Hakuho' peach trees planted at the Fruit Tree Rescearch Station in Tsukuba, Japan. Bloom date was 30 Mar. The temperature in the orchard was recorded with a platinum resistance thermometer placed $\approx 1.5 \mathrm{~m}$ above the ground.

Proton relaxation time measurement. The collected shoots were divided into three sets at each sampling time to obtain replicates for relaxation time measurement. Flower buds were taken from the central part of each shoot and placed in a 10-mmdiameter NMR sample-tube. Twenty five buds were used per replicate until early February. Because of the increase in bud 
volume, only 20 were used in late February, 15 in early March, and 3 in late March. The spin-lattice relaxation time (T1) of water protons in the flower buds was measured with a NMR spectrometer (FX-90Q; JEOL, Tokyo) by the inversion recovery (IR) method. With a 4500-Hz spectral width and a 3- to 5-sec pulse repetition time according to the $\mathrm{T} 1$, free induction decay (FID) was accumulated four times at $27 \mathrm{C}$, and 20 date points with different pulse intervals were collected for each sample for $\mathrm{T} 1$ calculation. The measurement time for a sample was $\approx 10 \mathrm{~min}$. The number of water components with a different $\mathrm{T} 1$, the population of each water component, and each $\mathrm{T} 1$ were determined from the resultant relaxation curve by a nonlinear least squares method using a subroutine of simplex written by Kobayashi (1981) on a computer (Yoshida and Nose, 1987).

Measurement of dry weight and freezable and nonfreezable water contents. Flower buds used for the determination of T1 were weighed and dried at $80 \mathrm{C}$ for 2 weeks. Their water content was calculated as the difference between fresh and dry weight.

The amount of freezable water in buds was measured once or twice monthly by DSC analysis according to the method of Hatakeyama et al. (1988). A bud was placed in a DSC cell, which was then sealed and weighed. The cell was then placed in a DSC 100 calorimeter (Seiko, Tokyo) linked with a SSC5000TA station. The instrument was calibrated using the heat of pure ice melting, $333 \mathrm{~J} / \mathrm{g}$. The sample was frozen at $-150 \mathrm{C}$ at a cooling rate of $5 \mathrm{C} /$ min and then the temperature was raised at the rate of $\mathrm{SC} / \mathrm{min}$ until it reached $60 \mathrm{C}$. The peak area of the thermograms was measured by assuming a linear base line between temperatures prior to and after melting. The amount of freezable water was calculated from the area by using a calibration constant. The bud was then pre-dried at $100 \mathrm{C}$ and dried under vacuum at $115 \mathrm{C}$ for $2 \mathrm{~h}$. The decrease in weight after drying was taken as the loss of total water. The unfrozen water content was obtained as the difference between the total water content and the freezable water content.

Estimation of the developmental stage. The shoots, from which some of the flower buds were taken for the T1 and DSC measurements, were put in a pail of water in a dark room at $20 \pm 0.5 \mathrm{C}$ and the humidity maintained at $80 \% \pm 10 \%$. The number of shoots in bloom was determined every day. A shoot was considered to have bloomed when at least one of its buds had flowered. The bloom date was defined as the date on which $30 \%$ of the shoots had bloomed. The percentage of bloom was calculated as (the number of shoots in bloom after 50 days' forcing/the number of all forced shoots) x 100 .

\section{Results}

Temperature and developmental stage of buds. The moving average of the previous 5 days temperature was low until early February. The temperature increased rapidly in February and decreased again in early March. After this cold period the temperature increased gradually until April (Fig. 1).

The percentage of bloom after forcing increased rapidly and reached $100 \%$ in early February (Fig. 1), indicating that the flower buds completed rest and entered into ecodormancy between 24 Jan. and 5 Feb. The number of days between sampling and bloom date decreased, indicating progressive development of the buds during ecodormancy. The number of days required for bloom decreased in February and March, but the rate decreased in early March, at which time the orchard temperature was lower than in late February and mid-March (Fig. 1).

Fresh weight, dry weight and water content. The fresh weight of the flower buds was almost constant from December to early

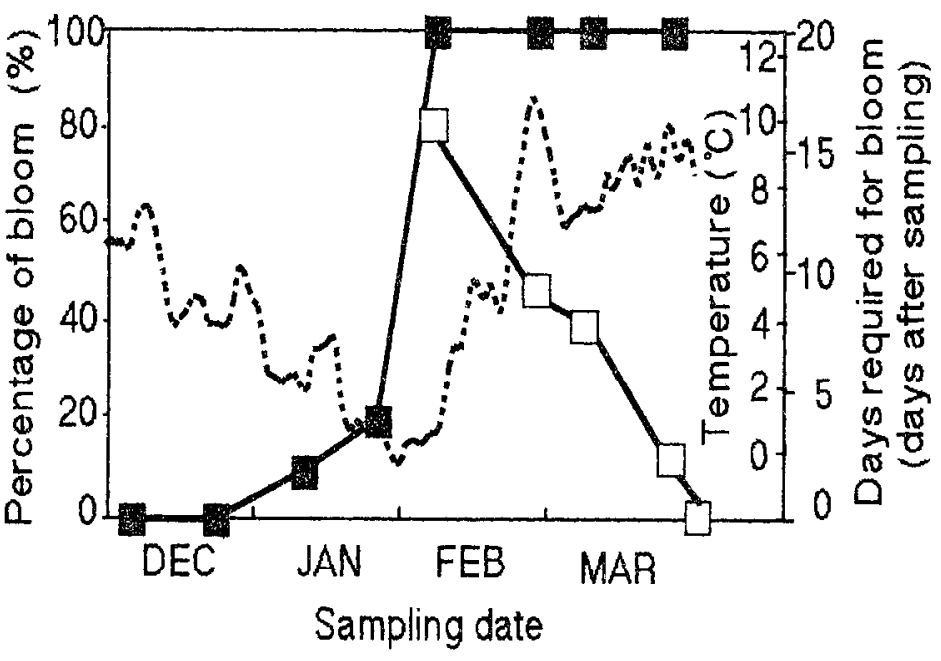

Fig. 1. Changes in moving average of the previous five days temperature (-----), the percentage of bloom after forcing ( $\mathbf{a})$ and the number of days between sampling and bloom date ( $\square$ ). Sample shoots were forced at 20C. The percentage of bloom was calculated 50 days after forcing and bloom date was defined as the date on which $30 \%$ of the shoots had bloomed.

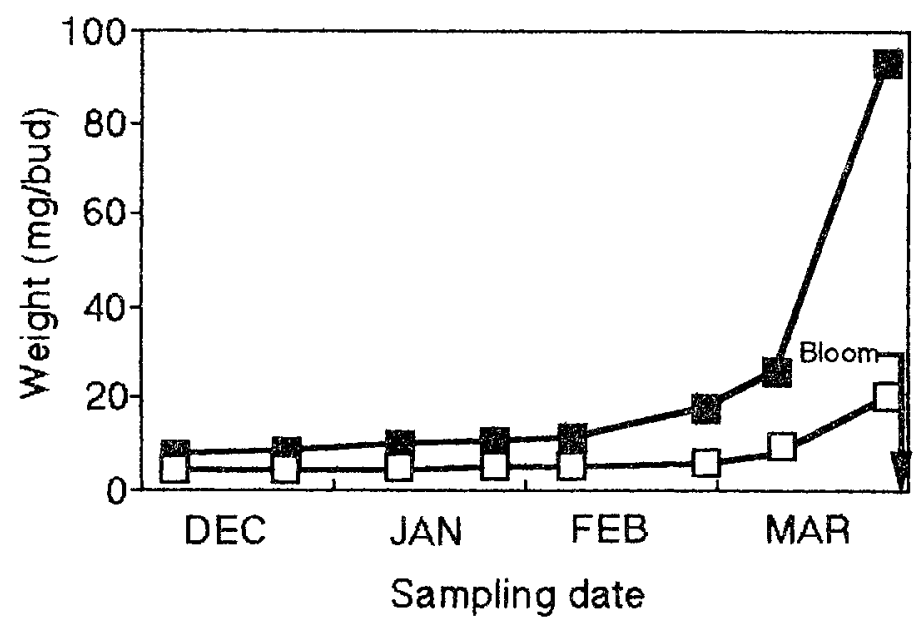

Fig. 2. Changes in fresh weight ( $\square$ ) and dry weight ( $\square$ ) of a peach flower bud

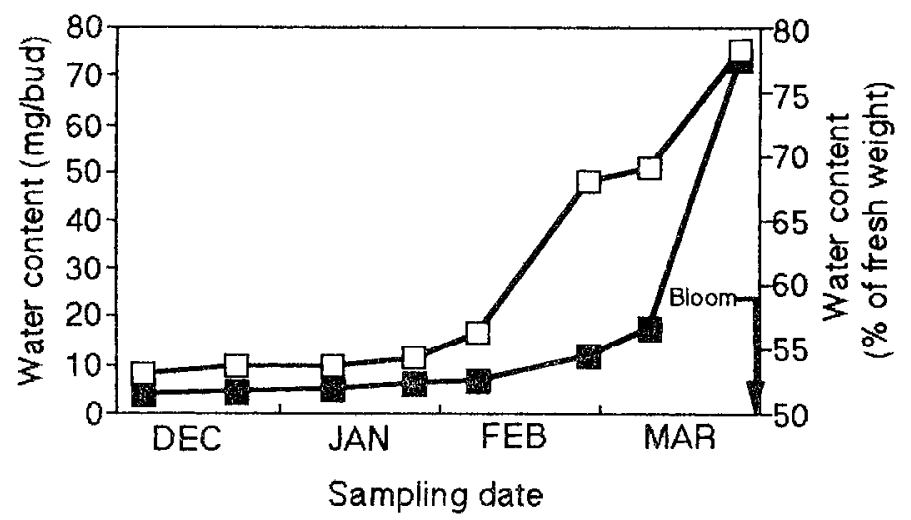

Fig. 3. Changes in water content ( $\mathbf{a}$ ) and water percentage as to fresh weight of a peach flower bud $(\square)$. 


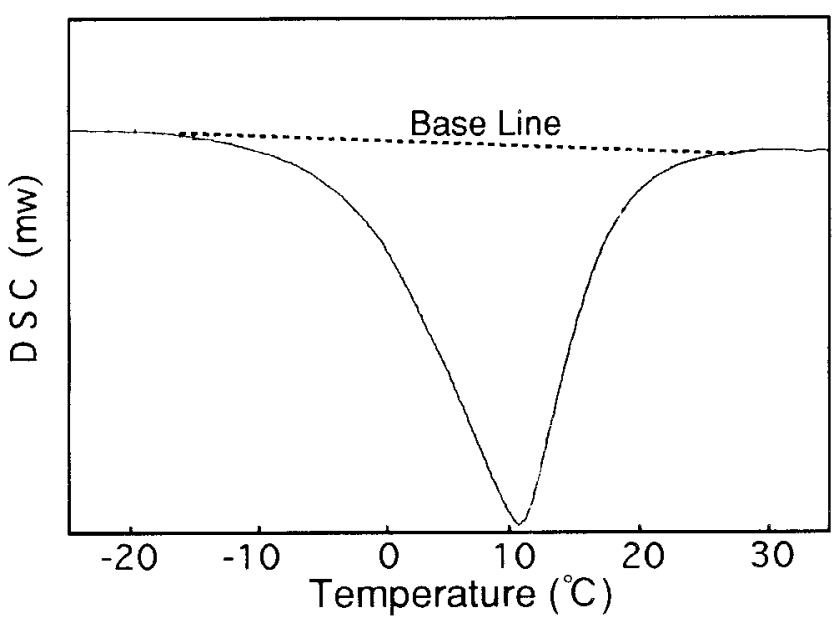

Fig. 4. DSC scan of a peach flower bud sampled in early December.

February, when their external appearance did not visibly change. The fresh weight increased slowly during February and rapidly in March (Fig. 2). which was accompanied by an increase in bud volume. The dry weight of the buds did not change greatly until early March. but increased after that (Fig. 2). Water content of the buds increased in February and the increase accelerated in late March (Fig. 3). This change was similar to that in the fresh weight. Water percentage expressed on a fresh weight basis increased slightly during endodormancy and increased rapidly in late February (Fig. 3). This dramatic change in water percentage occurred after endodormancy in early February and before the large increase in dry weight in late March. The rate of increase in the water percentage decreased in early March.

Freezable and nonfreezable water contents. One representative DSC scan is given in Fig 4. The onset temperature of the melting heat peaks was between -16.5 and $-14.5 \mathrm{C}$ and shifted in late February (Table 1).

The content of nonfreezable water was always less than that of frozen water. The percentage of unfrozen water relative to the total water decreased progressively from December to early March (Table 1). On the other hand. the amount of nonfreezable water per dry weight decreased until early January. The increase from late February (Table 1). was similar to the changes in the developmental stage and the water percentage during ecodormancy.

Water proton relaxation time. Two types of water were detected in the flower buds on NMR relaxation time analysis (Fig. 5). The water component with the longer T1 (T1L) was the major while the shorter T1 (T1S) was the minor component (Fig. 6).T1L increased slightly during endodormancy and increased greatly after early
February (Fig. 5). The change in T1L during ecodormancy coincided with progress in the developmental stage and an increase in the water percentage in the buds. T1S increased almost steadily from January, before endodormancy break, to March (Fig. 5). The increases in T1L and T1S were both lower in early March.

The content of the water with T1L (WL) was always larger than that of the water with T1S (WS). but the percentage of WL decreased as the time elapsed after early January, (Fig. 6). The difference between the percentage of WL and that of WS decreased sharply in late March just before bloom.

\section{Discussion}

The fresh weight of the buds, which did not change noticeably during endodormancy, began to increase in late February during ecodormancy and increased remarkably in late March. In contrast, the dry weight remained unchanged until early March. This indicates that ecodormancy can be divided into two phases. In the first phase, the buds begin to absorb water from vessels in the shoots. In the second phase, the dry weight increases rapidly in addition to the water absorption acceleration. Ashworth ( 1984) reported that xylem vessel elements are not observed within the floral primordia of peach buds dormant. Water enters into buds when vascular differentiation resumes and xylem continuity is established. relatively close to the time of bloom. This evidence suggests that vascular elements develop relatively earlier than other elements of the peach flower bud in ecodormancy.

Since the increase in water content began in February, earlier than the increase in the dry weight, the fresh weight percentage of water rose sharply in late February. This trend slowed in early March, when temperature was lower, but rapidly increased again in late March. This change reflected progress in the developmental stage of buds during ecodormancy as estimated from the bloom of the forced shoots. This suggests that progress in the developmental stage during ecodormancy is correlated with the increase in water content per dry matter, rather than with the increases in the dry weight and total water content in the buds.

The percentage of nonfreezable water relative to total water decreased while the freezing water content increased during endodormancy, during which time the total water content remained unchanged. These results support the suggestion that bound or structured water in apple buds changed into free water when the buds were chilled during endodormancy (Faust et al., 1991). It was demonstrated that intracellular water in tissues of very hardy species forms glass, which does not freeze (Hirsh et al., 1985), while nonfreezable water content per dry weight increased in midwinter (Vertucci and Stushnoff, 1992). But, in the present study, the unfrozen water content per dry weight increased from late February when the air temperature increased. It is possible that

Table 1. The onset temperature of melting heat peaks. the percentage of nonfreezing water relative to total water and the amount of nonfreezable water per dry weight for peach buds sampled at different times during endodormancy and ecodormancy. The nonfreezable water content was obtained as the difference between the total water content and the frozen water content determined by DSC analysis.

\begin{tabular}{|c|c|c|c|c|c|}
\hline \multirow[b]{2}{*}{ Date } & \multirow{2}{*}{$\begin{array}{l}\text { Onset lemperature } \\
\text { of melting }\left({ }^{\circ} \mathrm{C}\right)\end{array}$} & \multicolumn{2}{|c|}{ Nonfreezable water } & \multicolumn{2}{|c|}{ Nonfreezable water } \\
\hline & & (\% of total water) & SE & (dry weight) & SE \\
\hline Early Dec. & -16.5 & 23.6 & 0.04 & 0.32 & 0.009 \\
\hline Early Jan. & -16.5 & 18.2 & 0.11 & 0.24 & 0.037 \\
\hline Early Feb. & -16.5 & 17.1 & 0.36 & 0.24 & 0.007 \\
\hline Late Feb. & -15.0 & 17.9 & 0.56 & 0.35 & 0.011 \\
\hline Early Mar. & -15.0 & 14.3 & 0.26 & 0.35 & 0.007 \\
\hline Late Mar. & -14.5 & 14.7 & $2 . .27$ & 0.56 & 0.089 \\
\hline
\end{tabular}




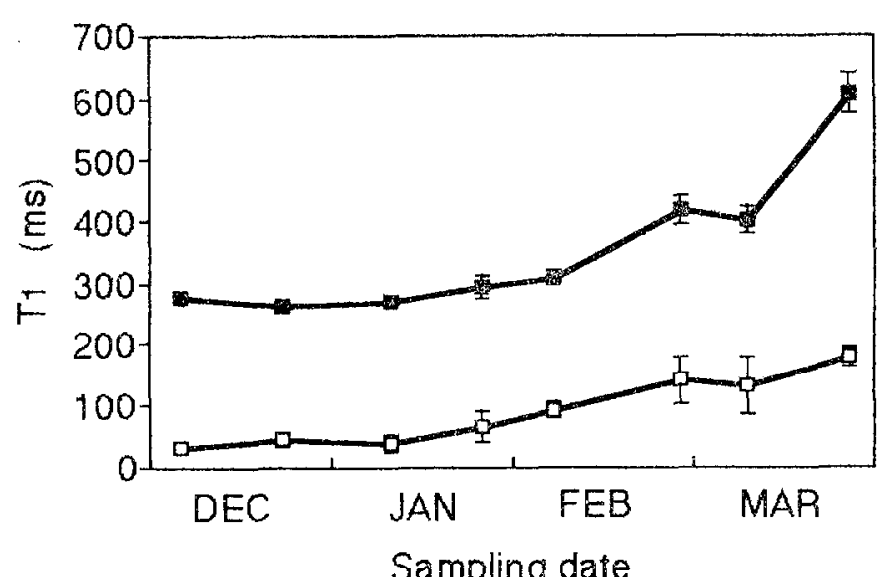

Fig. 5. Changes in spin-lattice relaxation time ( $\mathrm{T} 1$ ) of water protons in peach flower buds during endodormancy and ecodormancy. $A$ water component with a longer T1 (TIL, and a shorter T1 (TIS. D) were detected.

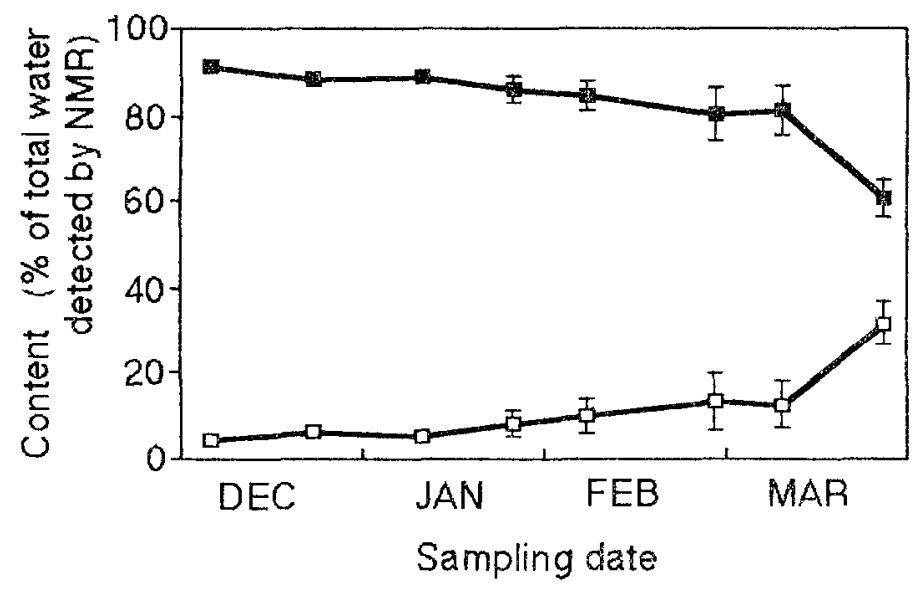

Fig. 6. Changes in the percentage of the water component with a longer T1. (WL. G) and that with a shorter T 1 ( WS, $\square$ ) in peach flower buds during endodormancy and ecodormancy.

the unfrozen water that incrcascd after early February may not bc glass that is formed to survive low temperaturc. but another type of water.

Different methods of calculating the amount of unfrozen water have been proposed in DSC experiments. In some DSC studies. calculations have been based on assuming that the heat ofmclting of water in solutions is $333 \mathbf{J} \cdot \mathrm{g}^{\prime}$ which is the heat ofmclting of pure water (Samygin and Livshin, 1970: Hatakeyama et al.. 1988) Recent studies have proposed another method of calculation of the amount of nonfreezable water (Vcrtucci and Stushnoff. 1992) bused on the demonstration that the heat of melting of water depends on the melting temperaturc (Gekko and Satakc. 1981) and the water content of the sample (Vertucci, 1990). In the present study, however, we calculated the amount of nonfreczable water using the heat of melting of water in buds as that of pure water. All samples had water contents above $53 \%$.

Two types of wutcr (WL and WS) with different T I (T 1 L and $\mathrm{T} 1 \mathrm{~S}$ ) were measured in the buds throughout endo- and ccodormancy. T1 L was 260 to $600 \mathrm{~ms}$ and T I S was 30 to $1 \mathrm{X} 0 \mathrm{~ms}$. The percentage of WS in the buds increased after early January, the increase being especially large just before bloom. Some reports of plant tissue water measured by NMR concluded that short relaxation times arc related to water bound to the cell wall and vessels, and long relaxation times arc related to free water in the cells (Gusta et al.. 1979: Bacic and Ratkovic. 1984:Balla et al.. 1985: Colirc et al.. 1988 ). Howcver the percentage of nonfreezing water ( $14 \%$ to 24 \%) determined bv DSC in our cxperiment was larger than that of WS (3\% to $12 \%$ ) except in late March. Moreover. the percentage of nonfrcering water decreased from Decemher to March, which did not corrclate with the change in WS percentage. WS may not be bc nonfreezing water. but a form of freczing wutcr like WL. We consider $\mathrm{T} 1$ of nonfreezing water in the buds to be too short to be detected by NMR measurements in this cxperiment. The TIS value reached $I 80 \mathrm{~ms}$. longer than the T1 values of bound watc reported in other papers (Gusta ct al..1979: Colire ct al., 1988). This value supports the presumption that WS. aswellas WL. is mobilewater, though the molecular mobility of WS is more restrictcd.

Ishida et al. (1987) assigned WS in soybeans to free wutcr in the cytoplasm and WL to free water in vacuoles. According to this hypothesis. our observation on the water in peach flower buds can be cxplained as follows: the cytoplasm absorbed water more rapidly than the vacuoles. and consequently the percentage of WS increased. Otsuka (1972) reported. however, that vacuoles in the cortex cells of mulberry began to grow in winter and swelled noticeably during ccodormancy. The vacuoles in the peach flower buds werealso expected to swell in ccodormancy. though WL decreased in that period. Thus. we could not shou that WL was water in vacuoles. We suggest that WL and WS arc distributed in the whole tissue.

The change in the T I L value corresponded to the progress in the developmental stage during ecodormancy as wellas the change in the water percentage as to the fresh weight. This suggests that the increase in T I L was derived from a decrease in the viscosity of the cellular water caused by water absorption by the cells. The watel proton $\mathrm{T}$ I has generally been reported Io be closely correlated with the water content in plant tissues (Gustaet al.. 1979; Kaku et al.. 1984: Colirc et al., 1988). Thus. T I L of flower buds can be used as an indicator of the physiological development in ecodormancy dominated by water absorption.

Although a remarkable change in T $1 \mathrm{~L}$ was not observed during endodormancy. Tl $\mathrm{S}$ incrcascd at a constant rate from shortly before the rest break until late February. This suggests that TIS may huve sonic relation with the physiological change at the rest break.

The water proton relaxation time measured by NMR reflects the viscosity of the cellular water. which depends upon water absorption by the cells. Its change also corresponds to progress in the developmental stage in ecodormancy. DSC data afford us information on changes in nonfreezing water content in flower buds which can not be detected by NMR. Thus. NMR and DSC analyses are useful for estimation of the physiological changes in buds according to the developmentalstage.

\section{Literature Cited}

Ashworth E.N. 1984. Xylem development in Prunus flower huds and the relationship to deep supercooling. Plant Physiol. 74:862-865.

Bacic. G. and S. Ratkovic. 1984. Water exchange in plant tissue studied by proton NMR in the presence of paramagnetic centers. Biophys. J. 45:767-776.

Balla. Y.I. N.G. Bakradze and Y.G. Sharimanov. 1985. Detection of two states of water in plant tissues by proton magnetic relaxation. Biophysics 30:522-528.

Chandler. W.H. and W.P. Tufts. 1934. Intluence of the rest period on opening of buds of fruit trees in spring and on development of flower buds of peach trees. Proc. Amer. Soc. Hort. Sci. 30:180-186. 
Colire, C., E.L. Rumeur, J. Gallier, J.D. Certaines, and F. Larher. 1988. An assessment of proton nuclear magnetic resonance as an alternative method to describe water status of leaf tissues in wilted plants. Plant Physiol. and Biochem. 26:767-776.

Corgan, J.N. and C. Peyton. 1970. Abscisic acid levels in dormant peach flower buds. J. Amer. Soc. Hort. Sci. 95:770-774.

Faust, M., D. Liu, M.M. Millard, and G.W. Stutte. 1991. Bound versus free water in dormant apple buds. A theory for endodormancy. HortScience 26:887-890.

Felker, F.C., H.A. Robitaille, and F.D. Hess. 1983. Morphological and ultrastructural development and starch accumulation during chilling of sour cherry flower buds. Amer. Jour. of Bot. 70:376-386.

Gekko K. and I. Satake. 1981. Differential scanning calorimetry of unfreezable water in water-protein-polyol systems. Agr. Biol. Chem. 45:2209-2217.

Gusta, L.V., D.B. Fowler, P. Chen, D.B. Russell, and D.G. Stout. 1979. A nuclear magnetic resonance study of water in cold-acclimating cereals. Plant Physiol. 63:627-634.

Harrison, M.A. and P.F. Saunders. 1975. The abscisic acid content of dormant birch buds. Planta 123:291-298.

Hatakeyama, T., K. Nakamura, H. Yoshida, and H. Hatakeyama. 1988 Determination of bound water content in polymers by DTA, DSC, and TG. Thermochimica Acta. 123:153-161.

Hirsh A.G., R.J. Williams, and H.T. Meryman. 1985. A novel method of natural cryoprotection. Plant Physiol. 79:41-56.

Ishida, N., H. Kano, T. Kobayashi, H. Hamaguchi, and T. Yoshida. 1987. Estimation of biological activities by NMR in soybean seeds during maturation. Agr. and Biol. Chem. 51:301-307.

Kaku, S., M. Iwaya-Inoue, and L.V. Gusta. 1984. Relationship of nuclear magnetic resonance relaxation time to water content and cold hardiness in flower buds of evergreen azalea. Plant and Cell Physiol. 25:875-882.
Kobayashi, K. 1981. A subroutine for function minimization by the simplex method. Bul. Computing Centre Res. Agri, For. Fisheries A17:51-71.

Mathur-De Vre R. 1984. Biomedical implications of the relaxation behavior of water related to NMR imaging. British Jour. of Radiol. 57:955-976.

Mielke, E.A. and F.G. Dennis. 1975. Hormonal control of flower bud dormancy in sour cherry (Prunus cerasus L.). II. Levels of abscisic acid and its water soluble complex. J. Amer. Soc. Hort. Sci. 100:287-290.

Otsuka, K. 1972. The ultrastructure of mulberry cortical parenchymacells related to the change of the freezing resistance in spring. Low Temp. Sci. Ser. B 30:33-44.

Samygin, G.A. and A.Z. Livshin. 1970. Water retaining forces in the cells of various plants in relation to their resistance to dehydration and freezing during the formation of extracellular ice. Sov. Plant Physiol. 72:114-119.

Seeley, S.D. and L.E. Powell. 198 I. Seasonal changes of free and hydrolyzable abscisic acid in vegetative apple buds. J. Amer. Soc. Hort. Sci. 106:405-409.

Vertucci, C.W. 1990. Calorimetric studies of the state of water in seed tissues. Biophys. J. 58:1463-1471

Vertucci, C.W. and C. Stushnoff. 1992. The state of water in acclimating vegetative buds from Malus and Amelunchier and its relationship to winter hardiness. Physiol. Plant. 86:503-511.

Wang, S.Y. and M. Faust. 1990. Changes of membrane lipids in apple buds during dormancy and budbreak. J. Amer. Soc. Hort. Sci. 115:803-808.

Wright, S.T.C. 1975. Seasonal changes in the levels of free and bound abscisic acid in blackcurrent (Ribes nigrum) and beech (Fagus sylyatica) buds. J. Expt. Bot. 26:161-174.

Yoshida, M. and K. Nose. 1987. Estimation of relaxation times of water protons in biological samples. Agr. and Biol. Chem. 51:3399-3401. 